\title{
Neurological complications during HIV infection
}

\author{
Jose M. Martinez-Navio* (D) \\ Department of Pathology, Miller School of Medicine, University of Miami, Miami, FL 33136, USA
}

*Correspondence: Jose M. Martinez-Navio, Department of Pathology, Miller School of Medicine, University of Miami, Miami, FL 33136, USA.martinez-navio@med.miami.edu

Academic Editor: Rafael Franco, Universitat de Barcelona, Spain

Received: April 12, 2021 Accepted: May 9, 2021 Published: August 5, 2021

Cite this article: Martinez-Navio JM. Neurological complications during HIV infection. Explor Neuroprot Ther. 2021;1:19-32. https://doi.org/10.37349/ent.2021.00004

\begin{abstract}
Early in the course of infection, human immunodeficiency virus (HIV) is able to enter the central nervous system where it stablishes a permanent reservoir. Current antiretroviral therapies do not efficiently cross the blood-brain barrier and therefore do not reach the HIV located in the central nervous system. Consequently, HIV infection can often be associated with neurocognitive impairment and HIV-associated dementia. The purpose of this review is to brief the reader into the world of neurological complications arising from HIV infection. Mechanisms by which HIV directly or indirectly impairs the central nervous system are discussed, as well as other factors influencing or contributing to the impairment, and the animal models currently used to perform research on the topic.
\end{abstract}

\section{Keywords}

HIV, neurological complications, HIV-associated neurocognitive disorders, dementia, inflammation

\section{Introduction}

Human immunodeficiency virus (HIV) is able to enter the central nervous system (CNS) early in the course of the infection where it stablishes a reservoir. In fact, the brain is seen as both, a reservoir and a hideaway for HIV [1, 2]. HIV infection can be efficiently suppressed with antiretroviral therapy (ART) but the existence of long-term reservoirs allows the viral load to rebound quickly after ART interruption. Therefore, HIV infection is currently chronic and incurable, requiring constant therapy to maintain clinical stability and low viral loads. Unfortunately, current antiretroviral therapies do not efficiently cross the blood-brain barrier (BBB) and therefore do not optimally reach the HIV found in the CNS [3-5]. Consequently, HIV infection can often be associated with neurological damage, including neurocognitive impairment and HIV-associated dementia (HAD) [6, 7]. Typical symptoms include loss of concentration, attention, and memory, irritability, depression, and slowed movements [8]. The severity of the symptoms can range from asymptomatic to HAD in the most severe cases.

Recent studies indicate that CNS impairment is at least partially induced by subtle damage in synapsis and dendrites, thus mediating disruption of neuronal networks in the brain that are involved in learning, 
memory and executive functions [8]. Because HIV replication in the CNS occurs principally in microglia (the resident macrophage-type cells), is thought that both, direct effects of viral proteins, and indirect effects mediated by microglia activation and secretion of neurotoxic products can contribute to neuronal damage $[9,10]$. However, the causes for such neurological dysfunctions are diverse and will be discussed in this review. Overall, HIV infection can cause disorders of the nervous system in at least three ways: 1) directly or indirectly by the HIV itself; 2 ) by complications related to the toxicity of the antiretroviral drugs used to control the viral loads; and 3) by opportunistic infections or certain cancers associated with HIV infection but not caused directly by the HIV virus.

\section{HIV infection}

HIV is a lentivirus that infects the very cells of the immune system in charge of fighting off incoming pathogens. There are two types of HIV: HIV-1 and HIV-2. Both originated by zoonotic transmission from non-human primates [11]. HIV-1 is a pandemic virus: approximately 36 million people are currently living with this virus around the world. Conversely, HIV-2 is predominantly present in West Africa. While HIV was discovered forty years ago, and despite strenuous efforts from the scientific community, a successful vaccine for this disease is yet to be found [12]. With almost a million deaths per year, the disease has become a global public health priority.

At the molecular level, the infection process is mediated by the HIV envelope spike, which attaches to cell-surface CD4 and then to a cellular co-receptor, such as chemokine receptors CXCR4 or CCR5. HIV infects predominantly CD4 helper T-cells but it can also infect macrophages, monocytes and dendritic cells. HIV infection is characterized by a progressive decline in number and function of CD4 T-cells, leaving the host vulnerable to opportunistic infections. If the HIV infection goes untreated, most individuals eventually develop acquired immunodeficiency syndrome (AIDS) and die in an 8-10 years' time-period. While both HIV-1 and HIV-2 can cause AIDS, HIV-1 mediates a faster decline of CD4 T-cells and onset of the disease [13]. Fortunately, due to the advent of ART, which is able to reduce the viral load to undetectable levels, AIDS-associated morbidity and mortality have significantly dropped. However, HIV is able to seed reservoirs early in infection, allowing the viral load to rebound after treatment interruption [14-16]. Thus, HIV infection is nowadays a chronic disease with the need for constant therapy to maintain clinical stability and low viral loads.

\section{Crossing barriers}

HIV is able to enter the CNS early in the course of infection, where it establishes a permanent reservoir. The CNS, which comprises brain, cerebellum and spinal cord, performs a plethora of key functions such as receiving and processing sensorial information, controlling voluntary and involuntary body movement, reflexes, and regulating homeostasis and body temperature. It is also where complex functions such as thinking, memory and learning reside. Due to its paramount importance, the CNS is protected and isolated from the rest of the body by the BBB. It has what is called immunoprivileged status $[17,18]$. The BBB is formed by brain endothelial cells sealed with tight junctions and is highly selective in restricting the transport of both, cells and molecules, from the blood into the CNS [19]. The CNS is surrounded by a colorless body fluid, different from blood: the cerebrospinal fluid (CSF). The tightly regulated protection imposed by the BBB is aimed at preventing pathogens from reaching the CNS and to help maintaining a constant and optimal local environment [18].

Both HIV-1 and HIV-2 are able to efficiently cross the BBB early in infection [20,21]. HIV can enter the CNS using a "Trojan horse" strategy: it infects monocytes or macrophages in the periphery, some of which will eventually cross the BBB, before the progeny viruses are released (see Figure 1). Moreover, free viruses can also transit across BBB through endothelial cells [22]. Once in the CNS, HIV is able to infect several cell types expressing CD4 on their cell-surface, including macrophages, microglia (also of macrophage lineage) and astrocytes [23, 24]. In fact, HIV isolates obtained from the CNS are mostly CCR5-using strains (i.e. with macrophage tropism) rather than CXCR4-using strains (i.e. with T-cell tropism) [9]. There has been some 
debate on whether neurons themselves can be infected with HIV [25]. While it has been reported [26, 27], neuronal infection seems largely non-productive, i.e. the virus is able to enter the cells but unable to produce a viral progeny [28].

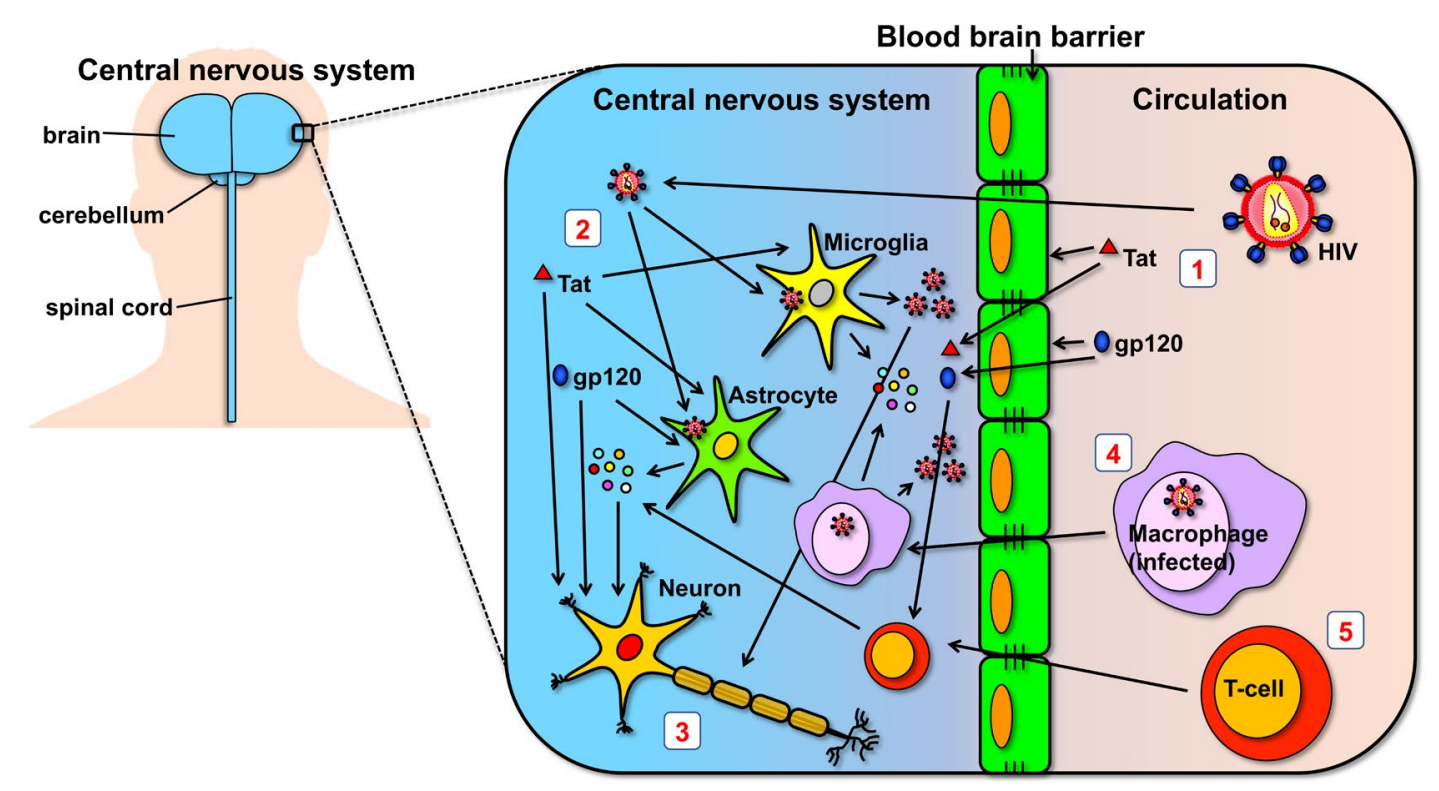

Figure 1. Summary of mechanisms of neuropathogenesis in the CNS. (1) HIV and HIV proteins glycoprotein 120 (gp120) and trans-activator of transcription (Tat) found in circulation are able to cross the BBB and reach the CNS. Importantly, they can cause direct damage to the cells forming the BBB; (2) once in the CNS, HIV is able to infect and replicate in microglia and astrocytes, cells which may also be affected by the direct toxic effects of Tat and gp120; (3) HIV virions and the two viral proteins, gp120 and Tat, can generate neuronal damage directly by acting on neurons, and indirectly by the cytokines that are released by bystander cells; (4) HIV can also cross the BBB by travelling inside macrophages which were infected in the periphery, using what is called the "Trojan horse" strategy; (5) similar to macrophages, T-cells can also infiltrate the CNS and have a role in neuroinflammatory processes. Although not indicated in the figure, HIV can also use T-cells as Trojan horses

Current antiretroviral therapies are extremely efficient at decreasing peripheral viral loads to undetectable levels. However, these drugs do not efficiently cross the BBB and therefore do not optimally reach the HIV found in the CNS [3-5]. Consequently, HIV infection can often be associated with neurological damage, including neurocognitive impairment and $\operatorname{HAD}[6,7]$.

\section{Neurological complications associated with HIV infection}

People living with HIV can frequently suffer from HIV-associated neurocognitive disorders (HAND). These disorders include three categories: asymptomatic neurocognitive impairment (ANI), mild neurocognitive disorder (MND), and HAD [29-31]. ANI, the mildest form of HAND is defined by substandard performance (1 standard deviation below the mean) in at least two of the so-called "cognitive areas", which include fine movement, fluency, executive functions and memory, when individuals are tested for such neurocognitive abilities. By definition, no impairment with daily functioning should be observed in the individual. While often these mild impairments, despite being detected by the aforementioned tests, can pass unnoticed by the affected individual, ANI is associated with an increased risk for symptomatic decline [29]. Therefore, early detection is important for proper management. The second form of HAND, MND, involves substandard performance ( 1 standard deviation below the mean) in at least two cognitive areas, similar to ANI, but with the addition of, at least mild, interference with daily functioning. Lastly, HAD is the most severe form of HAND. HAD is characterized by a worse performance in at least two of the aforementioned cognitive areas (2 standard deviations below the mean) and below-average performance in neuropsychological tests. Marked impairment in daily activities should be found too [29-31]. Besides these primary HAND, secondary cognitive limitations may also ensue, due to other factors.

Other common HAND include: a) peripheral neuropathy (HIV-related damage to peripheral neurons) [32]; b) vacuolar myelopathy, which is a disease of the spinal cord characterized by removal of the protective myelin 
sheath from nerve cells of the spinal cord, thus forming small holes or vacuoles. Symptoms include weak and stiff legs and shakiness when walking [33]. And lastly, c) immune reconstitution inflammatory syndrome (IRIS), which starts as an aberrant reconstituted immunity during ART and results in acute inflammatory responses in the host. Individuals with IRIS have a transient improvement of their HIV infection after starting ART, but then develop complications related to exacerbated inflammation [34]. IRIS can occur in two forms: "unmasking" IRIS, which refers to an exaggerated immune response developed towards a previously undiagnosed infection; and "paradoxical" IRIS, referring to the worsening of a previously recognized and treated infection. Importantly, IRIS can present in the CNS [35]. CNS-IRIS develops in a significant percentage (9-47\%) of people living with HIV who have an opportunistic infection in the CNS and start ART. Opportunistic infections in the CNS, such as toxoplasmosis, cryptococcal meningitis, and tuberculous meningitis, are not rare in untreated people living with HIV [36, 37]. Depending on the causative pathogen, the mortality rate of CNS-IRIS can vary from $13 \%$ to up to $75 \%$ [38].

The CNS is arguably one of the main targets of HIV-1 infection, but viral replication in this compartment is typically limited by the availability of target cells [20]. It is thought that the CNS is usually affected during the HIV primary infection, and that injury is innocuous and largely asymptomatic for the first few years. However, it can lead later on to HAND, stage at which many opportunistic infections can also affect the CNS [39].

\section{Viral proteins as neurotoxins}

The HIV virus encodes a number of proteins in its genome, some of which are known to cause damage to neural cells, including both neurons and neuroglia. The most well-known proteins to induce such problems are gp120 and Tat. Gp120 is part of the envelope or spike that the virus uses to enter the cells. Gp120 is often shed from infected cells or virions into circulation. Conversely, Tat is a small multifunctional protein involved in the control of the transcription of the HIV genome [40]. Despite having intracellular functions, Tat can be secreted [41] and has the intriguing property of entering bystander cells via a cell-penetrating peptide sequence [42]. Through this process, Tat can contribute to immune activation and cell death of bystander cells [43]. Importantly, both proteins have been found in CSF from HIV infected people, even when those individuals were under ART [44]. Accordingly, the effects of these proteins are not only seen in the periphery but also locally in the CNS (see Figure 1).

Gp120 has been identified as a potent neurotoxin promoting neurodegeneration via indirect and direct mechanisms involving interactions with CCR5 and CXCR4 $[45,46]$. Besides being found in immune cells, these chemokine receptors are also generally expressed in neurons and some other cell types in the CNS [45, 47]. Paradoxically, evidence for a CCR5-mediated neuroprotective pathway has also been demonstrated through heterologous desensitization of CXCR4 [48]. While mostly studied during HIV infection, CCR5 has also been linked to Alzheimer's disease [49], and it can influence neuron survival [47]. CCR5 has also been recognized as a therapeutic target for recovery after stroke and traumatic brain injury [50].

Gp120 has a role in disrupting costimulatory signals in T-cells, more specifically the adenosine deaminase (ADA)-CD26 axis [51]. ADA is an enzyme that can be found inside the cells, where it catabolizes adenosine; but also outside the cells, where it exerts both enzymatic and extra-enzymatic functions [52]. The ADA-CD26 interaction occurs on the cell surface and provides costimulatory signals during T-cell activation [53]. These signals are involved in T-cell differentiation, and the acquisition of immunological memory [53-56]. The gp120-mediated impairment of costimulation [51], and cytokine production [51, 54] may have significant relevance during HIV infection and AIDS pathogenesis [52, 57]. Because T-cells can infiltrate the CNS [58], it is reasonable to think that the HIV gp120 found in the CNS may disrupt the ADA-mediated costimulatory signals on those T-cells too. Emerging studies have shown a fundamental role for infiltrating T-cells in neuroinflammatory processes, as a key mechanistic piece leading to subsequent neurodegeneration in neurodegenerative disorders such as Parkinson's disease, Alzheimer's disease, amyotrophic lateral sclerosis and multiple sclerosis [59-62]. Because of the exacerbated inflammation associated with HIV infection, infected individuals may be more prone to develop such neurodegenerative diseases [63, 64]. 
Tat protein is known to contribute to neuropathogenesis in several ways, including its ability to be taken up by uninfected bystander CNS cells, and to activate inflammatory host genes causing synaptic injury [42]. Tat can also modulate proliferation and differentiation of human neural precursor cells [65] and impair neurogenesis [66].

Substance abuse seems to synergistically enhance the neurological damage mediated by some HIV proteins. For instance, methamphetamine and Tat protein cooperatively induce oxidative stress and BBB damage [67]. The presence of Tat in the CSF has been associated with previous abuse of psychostimulants, such as cocaine or amphetamines, and poorer performance in information processing and psychomotor speed [44]. Interestingly, it has been proposed that Tat in the CNS can mediate potentiation of the reward mechanisms associated with cocaine, opioid and alcohol use [68] and therefore potentiate the use of such substances. Glial CCR5 has also a critical role in directing neuropathological interactions of HIV-1 Tat and opiates [69].

In terms of treatment and management of HIV-related neurological complications, ART has been shown to improve cognitive function. In fact, increases in CD4 counts and decreases in viral loads correlate with cognitive improvement [70, 71]. However, despite management with ART, HIV-1 induced dysfunction of the CNS continues to persist. Important factors to consider include the different penetrability of the individual ART drugs in the CNS and their potential toxicity [72].

\section{ART-associated toxicity or virus-mediated damage?}

AIDS-associated morbidity and mortality have dropped considerably since the advent of ART in the mid 1990's. However, long-term use of antiretroviral therapy is not free of long-term complications. Some of the problems appear to relate to long-term side effects associated with the HIV medications themselves. These include lipodystrophy, insulin resistance, decrease in bone density, and lipid abnormalities [73]. Others, specifically chronic immune activation, inflammation, and hypercoagulation, seem to relate to the virus itself [74]. While a number of causes have been proposed, microbial translocation in gut is surely a critical factor [74-76]. It is also possible that some low-level replication of HIV in the presence of antiviral drugs could contribute to the chronic immune activation. It also seems probable that damage to the gut mucosa during the first weeks of HIV infection never gets adequately repaired, being an important factor in the chronic activation of the immune system in the face of effective therapy.

Chronic inflammation, and immune activation are key contributors to the CNS impairment. While ART can partially reverse the severity of the HIV-induced dysfunction in the CNS, the injure generally continues to persist. The problem likely relays on the bioavailability of the ART drugs in the brain, since they do not efficiently cross the BBB, and concentrations in the CSF are not an accurate measure of concentrations in the brain [77]. In an attempt to guide physicians, CNS penetration scores have been calculated for current ART drugs. While better scores have been correlated with more efficient suppression of CSF viral loads, and even some studies found improvement of HAND with that treatment, others could not find improvement in neurocognitive performance [77]. Differences may relate to the aforementioned disparities between drug concentration in CSF versus brain, since drug concentrations can be measured in the CSF but not in the brain, without risky invasive procedures. In some of these studies, enhanced CNS penetration was actually detrimental, highlighting that long-term use of ART can also result in toxicity to the CNS [77], which can exacerbate the damage from the virus itself.

All in all, while ART definitely helps in improving HAND and other neurological complications, long-term treatment can incur in toxicity to the CNS. Therefore, the selection of the ART combination must be done carefully. Novel drugs and therapeutic approaches are needed to improve the availability of ART drugs in the brain while reducing their toxicity $[39,72,77]$.

\section{Co-infections, cancer and external factors affecting the CNS}

People living with HIV are often more susceptible to other infections and certain types of cancer [78, 79]. Despite overall risks have significantly decreased during the ART era, common HIV co-infections include 
tuberculosis and hepatitis B and C. The types of cancer with higher incidence in the HIV positive population include Kaposi's sarcoma, Hodgkin's lymphoma, non-Hodgkin lymphoma, cervical cancer, anal cancer, liver cancer and lung cancer $[79,80]$. In terms of neurological impairment, hepatitis $\mathrm{C}$ virus (HCV) co-infection has been often associated with a greater risk for neurocognitive disorders in HIV infected individuals [81, 82]. This may be related to enhanced HCV-related immune activation, both systemic and in the CNS. In fact, chronic HCV infection has been associated with extrahepatic neurological conditions, even in the absence of HIV infection. Those affections include cerebrovascular events, encephalopathy, myelitis, cognitive impairment, and motor and sensory peripheral neuropathy (reviewed in [83] and [84]).

Other viruses that can negatively affect cognitive functions in HIV-infected individuals are Epstein-Barr virus (EBV) and Cytomegalovirus (CMV), due to increased inflammation [85]. EBV DNA can be detected in the CSF of many viremic individuals and some aviremic ones (on ART), and is associated with increased levels of neuronal damage and inflammation [86]. Higher levels of CMV and EBV DNA also correlated with multiple inflammatory markers and lower CD4/CD8 ratios [85] (the CD4/CD8 ratios are the number of CD4 T-cells per milliliter of blood divided by that of CD8 T-cells, and is usually between 1 and 4).

Neurosyphilis is caused by the bacterium Treponema pallidum when it reaches the CNS. Neurosyphilis is a complication of syphilis, a resurgent sexually transmitted disease. Progression to neurosyphilis is more common in individuals living with HIV $[87,88]$ and this may exacerbate ongoing neurological problems due to the HIV infection.

Important external factors that can exacerbate the damage to the CNS during HIV infection include the use of drugs and/or alcohol. Rates of substance use, abuse and dependence may often be higher among people living with HIV than comparable HIV negative populations [89]. A substantial minority of people living with HIV has comorbid substance use disorders which correlates with higher viral loads and less adherence to ART [90]. Overall, HIV infected individuals suffering from drug and/or alcohol abuse are at a greater risk of suffering neurocognitive disorders.

Depression and other mental health issues may also be exacerbated due to HIV infection and can contribute to poorer clinical outcomes.

\section{Aging in people living with HIV}

At the start of the HIV epidemic, newly diagnosed people could only expect to live a few years after their diagnosis. Therefore, issues related to aging were not a major focus at that time. Thanks to the development of successful ART able to control viral loads, people with HIV have now extended life expectancy, in some cases almost matching that of HIV negative individuals [91]. Therefore, the HIV population is an ever-aging population. For instance, according to the United States Centers for Disease Control and Prevention, of the estimated 1.2 million people living with HIV in 2018 in the U.S., about $51 \%$ were aged 50 and older. In addition, people aged 50 and older accounted for $17 \%$ of the new HIV diagnoses in the country that year. People living with HIV aged 50 and older are living longer, healthier lives because of effective ART. Nevertheless, the chronic inflammation observed during HIV infection, even in successfully treated individuals, appears to increase the risk for age-associated diseases. Furthermore, all effectively treated HIV-infected adults are increasingly manifesting signs of what is called "accelerated aging", which includes neurocognitive disorders (HAND), cardiovascular disease, osteoporosis, and kidney disease. Older adults are often at greater risk of HIV-related neurocognitive dysfunction [92] and because the population living with HIV is aging, HAND and other HIVrelated complications are already a growing problem [93].

\section{Animal models of HIV infection in the CNS}

The study of the neurological complications related to HIV infection has benefited from both in vitro models (reviewed by Faia et al. [94]) and in vivo models of HIV infection (reviewed by Mallard et al. [95]). Animal models have traditionally been very useful and complementary to research performed in human subjects across biomedical disciplines. Animal models allow for more controlled conditions in a laboratory setting, the use of more invasive techniques, extensive sampling, and the study of approaches otherwise not feasible or 
ethical to be performed in humans. Because CNS tissues are only available post-mortem, it is difficult to study HIV pathogenesis in living patients; therefore, animal models for the study of HIV pathogenesis in the brain have special relevance in this regard. Commonly used animal models to study effect of HIV in the CNS include rodents (mice and rats), and non-human primates. Because rodents are not naturally permissive to HIV infection, they have been generally used to test the neurotoxic effects of individual proteins from the virus. Remarkably, a transgenic rat model was developed, called HIV-1Tg rat, in which the rat brain contained seven of the nine genes encoded by the HIV genome, resulting in a non-infectious, long-term model of HIV protein exposure in the brain [96-99]. A mouse model was also developed in which HIV-1 infection can occur by viral re-targeting: the coding region of gp120 in HIV-1 was replaced with that of gp 80 from ecotropic murine leukemia virus, a retrovirus that infects only rodents. The resulting virus is called EcoHIV. EcoHIV infection of mice seems able to establish latent viral reservoirs in T cells and active viral reservoirs in macrophages which are sufficient for induction of neurocognitive impairment [100]. The EcoHIV virus model allows to study systemic infection and neuroinvasiveness in the mouse model [101, 102]. Such experiments have recently revealed a novel nonneurotoxic viral function in hippocampal synaptodendritic injury and memory impairment [102].

Another remarkable rodent model includes humanized mice, which are generated by implanting human tissues and/or injecting human cells into various strains of immunodeficient mice (reviewed in [103]). Several types have been developed: the c-HIVE model in which HIV-infected myeloid cells are injected directly into the brains of severe combined immunodeficient (SCID) mice, to see if they contribute or not to HIVassociated encephalitis (HIVE); the PBMC-transplanted mice, in which human peripheral blood mononuclear cells (PBMCs) are inoculated; the hematopoietic stem cells-transplanted mice; and the "myeloid only mouse model", to cite a few (see [103] for further details).

While murine animal models have certain limitations, such as divergent receptor sequence with humans, or differences in regional expression of cellular receptors [99], most of them have relatively low cost and allow for large sample size.

The most physiologically relevant model for HIV and HIV-related neurological complications is the non-human primate model. Genetically speaking, monkeys are more closely related to humans than rats or mice. Importantly, certain simian immunodeficiency viruses (SIVs) can induce AIDS in infected monkeys in a process that recapitulates the infection course seen in humans with HIV [104]. Several non-human primate models of neuroAIDS exist (reviewed in [105]). Traditionally rhesus macaques or pigtail macaques have been mostly used, together with different SIV clones or swarms able to induce AIDS, which had macrophage tropism, and induced SIV encephalitis [105]. Interestingly, some SIVs can induce rapid AIDS with progression to AIDS within 6 months after infection, like SIVmac17E-Fr [106]. While for others it may take longer (like for SIVmac239, SIVmac316 or SIVmac251) [95, 105, 107] and therefore better reflect the tempo of neuroAIDS progression in humans. Another molecular clone, namely SIVsm804E, is able to target the CNS and efficiently induce neuroAIDS in rhesus macaques [108]. A variant originated from that clone, SIVsm804E-CL757, causes a more delayed progression to AIDS, inducing encephalitis in a high proportion of inoculated animals, with high CSF viral loads, and multinucleated giant cells (microglial and/or macrophage cells that fuse with each other) in the CNS $[108,109]$.

Animal models have proven especially useful for research on substance abuse and HIV comorbidity [97, 110-114]. For instance, animal experiments have shown evidence that the presence of HIV-1 viral proteins in the CNS increases the sensitivity and susceptibility of HIV-positive individuals to substance abuse [97]. Continued research on the manifestation and mechanisms of neurological injury in HAND patients is needed. Animal models will be critical to help develop safe and effective therapies that reverse neuropathology and cognitive impairment [8].

\section{Conclusion}

People living with HIV can suffer serious neurological complications in at least three ways: 1) by mechanisms related to the HIV infection itself; 2) by the toxicity induced by the long-term use of ART used to control the 
HIV viral loads; and 3) by opportunistic infections and certain cancers associated with HIV infection but not caused directly by the HIV virus. Due to longer life expectancies in people living with HIV and an aging population, the severity of the symptoms and the number of people affected are expected to increase over time. While efforts continue to find a cure or vaccine for this disease, strategies for early detection, treatment, and mitigation of neurological complications of HIV infection are warranted.

\section{Abbreviations}

ADA: adenosine deaminase

AIDS: acquired immunodeficiency syndrome

ANI: asymptomatic neurocognitive impairment

ART: antiretroviral therapy

BBB: blood-brain barrier

CNS: central nervous system

CSF: cerebrospinal fluid

DNA: deoxyribonucleic acid

EBV: Epstein-Barr virus

gp120: glycoprotein 120

HAD: human immunodeficiency virus-associated dementia

HAND: human immunodeficiency virus-associated neurocognitive disorders

HCV: hepatitis $C$ virus

HIV: human immunodeficiency virus

IRIS: immune reconstitution inflammatory syndrome

SIV: simian immunodeficiency virus

Tat: trans-activator of transcription

\section{Declarations}

\section{Author contributions}

The author contributed solely to the work.

\section{Conflicts of interest}

The author declares no conflicts of interest.

\section{Ethical approval}

Not applicable.

\section{Consent to participate}

Not applicable.

\section{Consent to publication}

Not applicable.

\section{Availability of data and materials}

Not applicable.

\section{Funding}

Not applicable. 


\section{Copyright}

(C) The Author(s) 2021.

\section{References}

1. Machado Andrade V, Stevenson M. Host and viral factors influencing interplay between the macrophage and HIV-1. J Neuroimmune Pharmacol. 2019;14:33-43.

2. Canet G, Dias C, Gabelle A, Simonin Y, Gosselet F, Marchi N, et al. HIV neuroinfection and Alzheimer's disease: similarities and potential links? Front Cell Neurosci. 2018;12:307.

3. Decloedt EH, Rosenkranz B, Maartens G, Joska J. Central nervous system penetration of antiretroviral drugs: pharmacokinetic, pharmacodynamic and pharmacogenomic considerations. Clin Pharmacokinet. 2015;54:581-98.

4. Omeragic A, Kayode O, Hoque MT, Bendayan R. Potential pharmacological approaches for the treatment of HIV-1 associated neurocognitive disorders. Fluids Barriers CNS. 2020;17:42.

5. Osborne O, Peyravian N, Nair M, Daunert S, Toborek M. The paradox of HIV blood-brain barrier penetrance and antiretroviral drug delivery deficiencies. Trends Neurosci. 2020;43:695-708.

6. Minagar A, Commins D, Alexander JS, Hoque R, Chiappelli F, Singer EJ, et al. NeuroAIDS: characteristics and diagnosis of the neurological complications of AIDS. Mol Diagn Ther. 2008;12:25-43.

7. Ene L. Human immunodeficiency virus in the brain-culprit or facilitator? Infect Dis (Auckl). 2018;11:1178633717752687.

8. Irollo E, Luchetta J, Ho C, Nash B, Meucci O. Mechanisms of neuronal dysfunction in HIV-associated neurocognitive disorders. Cell Mol Life Sci. 2021;78:4283-303.

9. Yi Y, Lee C, Liu QH, Freedman BD, Collman RG. Chemokine receptor utilization and macrophage signaling by human immunodeficiency virus type 1 gp120: implications for neuropathogenesis. J Neurovirol. 2004;10 Suppl 1:91-6.

10. Borrajo A, Spuch C, Penedo MA, Olivares JM, Agís-Balboa RC. Important role of microglia in HIV-1 associated neurocognitive disorders and the molecular pathways implicated in its pathogenesis. Ann Med. 2021;53:43-69.

11. Sharp PM, Hahn BH. Origins of HIV and the AIDS pandemic. Cold Spring Harb Perspect Med. 2011;1:a006841.

12. Martinez-Navio JM, Desrosiers RC. Vaccine efforts against AIDS. In: Hope TJ, Richman D, Stevenson M, editors. Encyclopedia of AIDS. New York:Springer; 2016. p. 1-12.

13. Vidya Vijayan KK, Karthigeyan KP, Tripathi SP, Hanna LE. Pathophysiology of CD4+ T-cell depletion in HIV-1 and HIV-2 infections. Front Immunol. 2017;8:580.

14. García F, Plana M, Vidal C, Cruceta A, O’Brien WA, Pantaleo G, et al. Dynamics of viral load rebound and immunological changes after stopping effective antiretroviral therapy. AIDS. 1999;13:F79-86.

15. Saksena NK, Haddad DN. Viral reservoirs an impediment to HAART: new strategies to eliminate HIV-1. Curr Drug Targets Infect Disord. 2003;3:179-206.

16. Hendricks CM, Cordeiro T, Gomes AP, Stevenson M. The interplay of HIV-1 and macrophages in viral persistence. Front Microbiol. 2021;12:646447.

17. Huber AK, Irani DN. Is the concept of central nervous system immune privilege irrelevant in the setting of acute infection? Front Oncol. 2015;5:99.

18. Forrester JV, McMenamin PG, Dando SJ. CNS infection and immune privilege. Nat Rev Neurosci. 2018;19:655-71.

19. Daneman R, Prat A. The blood-brain barrier. Cold Spring Harb Perspect Biol. 2015;7:a020412.

20. Joseph SB, Arrildt KT, Sturdevant CB, Swanstrom R. HIV-1 target cells in the CNS. J Neurovirol. 2015;21:276-89. 
21. Mörner A, Thomas JA, Björling E, Munson PJ, Lucas SB, McKnight A. Productive HIV-2 infection in the brain is restricted to macrophages/microglia. AIDS. 2003;17:1451-5.

22. Lorin V, Danckaert A, Porrot F, Schwartz O, Afonso PV, Mouquet H. Antibody neutralization of HIV-1 crossing the blood-brain barrier. mBio. 2020;11:e02424-20.

23. Lutgen V, Narasipura SD, Barbian HJ, Richards M, Wallace J, Razmpour R, et al. HIV infects astrocytes in vivo and egresses from the brain to the periphery. PLoS Pathog. 2020;16:e1008381.

24. Eugenin EA, Clements JE, Zink MC, Berman JW. Human immunodeficiency virus infection of human astrocytes disrupts blood-brain barrier integrity by a gap junction-dependent mechanism. J Neurosci. 2011;31:9456-65.

25. Bissel SJ, Wiley CA. Human immunodeficiency virus infection of the brain: pitfalls in evaluating infected/ affected cell populations. Brain Pathol. 2004;14:97-108.

26. Harouse JM, Kunsch C, Hartle HT, Laughlin MA, Hoxie JA, Wigdahl B, et al. CD4-independent infection of human neural cells by human immunodeficiency virus type 1. J Virol. 1989;63:2527-33.

27. Alvarez Losada S, Cantó-Nogués C, Muñoz-Fernández MA. A new possible mechanism of human immunodeficiency virus type 1 infection of neural cells. Neurobiol Dis. 2002;11:469-78.

28. Kovalevich J, Langford D. Neuronal toxicity in HIV CNS disease. Future Virol. 2012;7:687-98.

29. Grant I, Franklin DR Jr, Deutsch R, Woods SP, Vaida F, Ellis RJ, et al. Asymptomatic HIV-associated neurocognitive impairment increases risk for symptomatic decline. Neurology. 2014;82:2055-62.

30. Rourke SB, Bekele T, Rachlis A, Kovacs C, Brunetta J, Gill MJ, et al. Asymptomatic neurocognitive impairment is a risk for symptomatic decline over a 3-year study period. AIDS. 2021;35:63-72.

31. Mitra P. HIV neurocognitive disorders [Internet]. Sharman T, editor. Treasure Island (FL): StatPearls Publishing; 2021 [cited 2021 Apr 10]. Available from: https://www.statpearls.com/articlelibrary/ viewarticle/20340/

32. Wang SXY, Ho EL, Grill M, Lee E, Peterson J, Robertson K, et al. Peripheral neuropathy in primary HIV infection associates with systemic and central nervous system immune activation. J Acquir Immune Defic Syndr. 2014;66:303-10.

33. Rezaie A, Parmar R, Rendon C, Zell SC. HIV-associated vacuolar myelopathy: a rare initial presentation of HIV. SAGE Open Med Case Rep. 2020;8:2050313X20945562.

34. Manzardo C, Guardo AC, Letang E, Plana M, Gatell JM, Miro JM. Opportunistic infections and immune reconstitution inflammatory syndrome in HIV-1-infected adults in the combined antiretroviral therapy era: a comprehensive review. Expert Rev Anti Infect Ther. 2015;13:751-67.

35. Bowen L, Nath A, Smith B. CNS immune reconstitution inflammatory syndrome. Handb Clin Neurol. 2018;152:167-76.

36. Bowen LN, Smith B, Reich D, Quezado M, Nath A. HIV-associated opportunistic CNS infections: pathophysiology, diagnosis and treatment. Nat Rev Neurol. 2016;12:662-74.

37. Thakur KT. CNS infections in HIV. Curr Opin Infect Dis. 2020;33:267-72.

38. Bahr N, Boulware DR, Marais S, Scriven J, Wilkinson RJ, Meintjes G. Central nervous system immune reconstitution inflammatory syndrome. Curr Infect Dis Rep. 2013;15:583-93.

39. Ghosh AK, Sarkar A, Mitsuya H. HIV-associated neurocognitive disorder (HAND) and the prospect of brain-penetrating protease inhibitors for antiretroviral treatment. Med Res Arch. 2017;5:1113.

40. Rice AP. The HIV-1 Tat protein: mechanism of action and target for HIV-1 cure strategies. Curr Pharm Des. 2017;23:4098-102.

41. Mele AR, Marino J, Chen K, Pirrone V, Janetopoulos C, Wigdahl B, et al. Defining the molecular mechanisms of HIV-1 Tat secretion: PtdIns(4,5) $\mathrm{P}_{2}$ at the epicenter. Traffic. 2018;19:655-65. 
42. Ruiz AP, Ajasin DO, Ramasamy S, DesMarais V, Eugenin EA, Prasad VR. A naturally occurring polymorphism in the HIV-1 Tat basic domain inhibits uptake by bystander cells and leads to reduced neuroinflammation. Sci Rep. 2019;9:3308.

43. Ajasin D, Eugenin EA. HIV-1 Tat: role in bystander toxicity. Front Cell Infect Microbiol. 2020;10:61.

44. Henderson LJ, Johnson TP, Smith BR, Reoma LB, Santamaria UA, Bachani M, et al. Presence of Tat and transactivation response element in spinal fluid despite antiretroviral therapy. AIDS. 2019;33 Suppl 2:S145-57.

45. Smith LK, Kuhn TB, Chen J, Bamburg JR. HIV associated neurodegenerative disorders: a new perspective on the role of lipid rafts in gp120-mediated neurotoxicity. Curr HIV Res. 2018;16:258-69.

46. Smith LK, Babcock IW, Minamide LS, Shaw AE, Bamburg JR, Kuhn TB. Direct interaction of HIV gp120 with neuronal CXCR4 and CCR5 receptors induces cofilin-actin rod pathology via a cellular prion protein- and NOX-dependent mechanism. PLoS One. 2021;16:e0248309.

47. Sorce S, Myburgh R, Krause KH. The chemokine receptor CCR5 in the central nervous system. Prog Neurobiol. 2011;93:297-311.

48. Kaul M, Ma Q, Medders KE, Desai MK, Lipton SA. HIV-1 coreceptors CCR5 and CXCR4 both mediate neuronal cell death but CCR5 paradoxically can also contribute to protection. Cell Death Differ. 2007;14: 296-305.

49. Li T, Zhu J. Entanglement of CCR5 and Alzheimer's disease. Front Aging Neurosci. 2019;11:209.

50. Joy MT, Ben Assayag E, Shabashov-Stone D, Liraz-Zaltsman S, Mazzitelli J, Arenas M, et al. CCR5 is a therapeutic target for recovery after stroke and traumatic brain injury. Cell. 2019;176:1143-57.e13.

51. Martinez-Navio JM, Climent N, Pacheco R, Garcia F, Plana M, Nomdedeu M, et al. Immunological dysfunction in HIV-1-infected individuals caused by impairment of adenosine deaminase-induced costimulation of T-cell activation. Immunology. 2009;128:393-404.

52. Franco R, Pacheco R, Gatell JM, Gallart T, Lluis C. Enzymatic and extraenzymatic role of adenosine deaminase 1 in T-cell-dendritic cell contacts and in alterations of the immune function. Crit Rev Immunol. 2007;27:495-509.

53. Pacheco R, Martinez-Navio JM, Lejeune M, Climent N, Oliva H, Gatell JM, et al. CD26, adenosine deaminase, and adenosine receptors mediate costimulatory signals in the immunological synapse. Proc Natl Acad Sci U S A. 2005;102:9583-8.

54. Climent N, Martinez-Navio JM, Gil C, Garcia F, Rovira C, Hurtado C, et al. Adenosine deaminase enhances T-cell response elicited by dendritic cells loaded with inactivated HIV. Immunol Cell Biol. 2009;87:634-9.

55. Martinez-Navio JM, Casanova V, Pacheco R, Naval-Macabuhay I, Climent N, Garcia F, et al. Adenosine deaminase potentiates the generation of effector, memory, and regulatory CD4 $4^{+} \mathrm{T}$ cells. J Leukoc Biol. 2011;89:127-36.

56. Naval-Macabuhay I, Casanova V, Navarro G, Garcia F, Leon A, Miralles L, et al. Adenosine deaminase regulates Treg expression in autologous $\mathrm{T}$ cell-dendritic cell cocultures from patients infected with HIV1. J Leukoc Biol. 2016;99:349-59.

57. Passos DF, Bernardes VM, da Silva JLG, Schetinger MRC, Leal DBR. Adenosine signaling and adenosine deaminase regulation of immune responses: impact on the immunopathogenesis of HIV infection. Purinergic Signal. 2018;14:309-20.

58. Korn T, Kallies A. T cell responses in the central nervous system. Nat Rev Immunol. 2017;17:179-94.

59. Campos-Acuña J, Elgueta D, Pacheco R. T-cell-driven inflammation as a mediator of the gut-brain axis involved in Parkinson's disease. Front Immunol. 2019;10:239.

60. González H, Contreras F, Pacheco R. Regulation of the neurodegenerative process associated to Parkinson's disease by CD4+ T-cells. J Neuroimmune Pharmacol. 2015;10:561-75. 
61. González H, Pacheco R. T-cell-mediated regulation of neuroinflammation involved in neurodegenerative diseases. J Neuroinflammation. 2014;11:201.

62. González H, Elgueta D, Montoya A, Pacheco R. Neuroimmune regulation of microglial activity involved in neuroinflammation and neurodegenerative diseases. J Neuroimmunol. 2014;274:1-13.

63. Tisch S, Brew B. Parkinsonism in HIV-infected patients on highly active antiretroviral therapy. Neurology. 2009;73:401-3.

64. Dehner LF, Spitz M, Pereira JS. Parkinsonism in HIV infected patients during antiretroviral therapy-data from a Brazilian tertiary hospital. Braz J Infect Dis. 2016;20:499-501.

65. Mishra M, Taneja M, Malik S, Khalique H, Seth P. Human immunodeficiency virus type 1 Tat modulates proliferation and differentiation of human neural precursor cells: implication in NeuroAIDS. J Neurovirol. 2010;16:355-67.

66. Fan Y, Gao X, Chen J, Liu Y, He JJ. HIV Tat impairs neurogenesis through functioning as a Notch ligand and activation of Notch signaling pathway. J Neurosci. 2016;36:11362-73.

67. Huang J, Zhang R, Wang S, Zhang D, Leung CK, Yang G, et al. Methamphetamine and HIV-Tat protein synergistically induce oxidative stress and blood-brain barrier damage via transient receptor potential melastatin 2 channel. Front Pharmacol. 2021;12:619436.

68. Cirino T], McLaughlin JP. Mini review: promotion of substance abuse in HIV patients: biological mediation by HIV-1 Tat protein. Neurosci Lett. 2021;753:135877.

69. Kim S, Hahn YK, Podhaizer EM, McLane VD, Zou S, Hauser KF, et al. A central role for glial CCR5 in directing the neuropathological interactions of HIV-1 Tat and opiates. J Neuroinflammation. 2018;15:285.

70. Fitri FI, Rambe AS, Fitri A. Correlation between lymphocyte CD4 count, treatment duration, opportunistic infection and cognitive function in human immunodeficiency virus-acquired immunodeficiency syndrome (HIV-AIDS) patients. Open Access Maced J Med Sci. 2018;6:643-7.

71. Tozzi V, Balestra P, Bellagamba R, Corpolongo A, Salvatori MF, Visco-Comandini U, et al. Persistence of neuropsychologic deficits despite long-term highly active antiretroviral therapy in patients with HIV-related neurocognitive impairment: prevalence and risk factors. J Acquir Immune Defic Syndr. 2007;45:174-82.

72. Kumar S, Maurya VK, Dandu HR, Bhatt ML, Saxena SK. Global perspective of novel therapeutic strategies for the management of neuroAIDS. Biomol Concepts. 2018;9:33-42.

73. Chawla A, Wang C, Patton C, Murray M, Punekar Y, de Ruiter A, et al. A review of long-term toxicity of antiretroviral treatment regimens and implications for an aging population. Infect Dis Ther. 2018;7:183-95.

74. Deeks SG, Tracy R, Douek DC. Systemic effects of inflammation on health during chronic HIV infection. Immunity. 2013;39:633-45.

75. Marchetti G, Tincati C, Silvestri G. Microbial translocation in the pathogenesis of HIV infection and AIDS. Clin Microbiol Rev. 2013;26:2-18.

76. Sandler NG, Douek DC. Microbial translocation in HIV infection: causes, consequences and treatment opportunities. Nat Rev Microbiol. 2012;10:655-66.

77. Nicol MR, McRae M. Treating viruses in the brain: perspectives from NeuroAIDS. Neurosci Lett. 2021;748:135691.

78. Silverberg MJ, Chao C, Leyden WA, Xu L, Tang B, Horberg MA, et al. HIV infection and the risk of cancers with and without a known infectious cause. AIDS. 2009;23:2337-45.

79. Hernández-Ramírez RU, Shiels MS, Dubrow R, Engels EA. Cancer risk in HIV-infected people in the USA from 1996 to 2012: a population-based, registry-linkage study. Lancet HIV. 2017;4:e495-504.

80. Gonçalves PH, Uldrick TS, Yarchoan R. HIV-associated Kaposi sarcoma and related diseases. AIDS. 2017;31:1903-16. 
81. de Almeida SM, de Pereira AP, Pedroso MLA, Ribeiro CE, Rotta I, Tang B, et al. Neurocognitive impairment with hepatitis C and HIV co-infection in Southern Brazil. J Neurovirol. 2018;24:339-49.

82. Barokar J, McCutchan A, Deutsch R, Tang B, Cherner M, Bharti AR. Neurocognitive impairment is worse in HIV/HCV-coinfected individuals with liver dysfunction. J Neurovirol. 2019;25:792-9.

83. Adinolfi LE, Nevola R, Lus G, Restivo L, Guerrera B, Romano C, et al. Chronic hepatitis C virus infection and neurological and psychiatric disorders: an overview. World J Gastroenterol. 2015;21:2269-80.

84. Monaco S, Mariotto S, Ferrari S, Calabrese M, Zanusso G, Gajofatto A, et al. Hepatitis C virusassociated neurocognitive and neuropsychiatric disorders: advances in 2015. World J Gastroenterol. 2015;21:11974-83.

85. Gianella S, Moser C, Vitomirov A, McKhann A, Layman L, Scott B, et al. Presence of asymptomatic cytomegalovirus and Epstein--Barr virus DNA in blood of persons with HIV starting antiretroviral therapy is associated with non-AIDS clinical events. AIDS. 2020;34:849-57.

86. Lupia T, Milia MG, Atzori C, Gianella S, Audagnotto S, Imperiale D, et al. Presence of Epstein-Barr virus DNA in cerebrospinal fluid is associated with greater HIV RNA and inflammation. AIDS. 2020;34:373-80.

87. Dumaresq J, Langevin S, Gagnon S, Serhir B, Deligne B, Tremblay C, et al. Clinical prediction and diagnosis of neurosyphilis in HIV-infected patients with early Syphilis. J Clin Microbiol. 2013;51:4060-6.

88. Hobbs E, Vera JH, Marks M, Barritt AW, Ridha BH, Lawrence D. Neurosyphilis in patients with HIV. Pract Neurol. 2018;18:211-8.

89. Durvasula R, Miller TR. Substance abuse treatment in persons with HIV/AIDS: challenges in managing triple diagnosis. Behav Med. 2014;40:43-52.

90. Carrico AW, Johnson MO, Moskowitz JT, Neilands TB, Morin SF, Charlebois ED, et al. Affect regulation, stimulant use, and viral load among HIV-positive persons on anti-retroviral therapy. Psychosom Med. 2007;69:785-92.

91. Marcus JL, Leyden WA, Alexeeff SE, Anderson AN, Hechter RC, Hu H, et al. Comparison of overall and comorbidity-free life expectancy between insured adults with and without HIV infection, 2000-2016. JAMA Netw Open. 2020;3:e207954.

92. Cherner M, Ellis RJ, Lazzaretto D, Young C, Mindt MR, Atkinson JH, et al. Effects of HIV-1 infection and aging on neurobehavioral functioning: preliminary findings. AIDS. 2004;18 Suppl 1:S27-34.

93. Smit M, Brinkman K, Geerlings S, Smit C, Thyagarajan K, van Sighem A, et al. Future challenges for clinical care of an ageing population infected with HIV: a modelling study. Lancet Infect Dis. 2015;15:810-8.

94. Faia C, Plaisance-Bonstaff K, Peruzzi F. In vitro models of HIV-1 infection of the Central Nervous System. Drug Discov Today Dis Models. 2020;32:5-11.

95. Mallard J, Williams KC. Animal models of HIV-associated disease of the central nervous system. Handb Clin Neurol. 2018;152:41-53.

96. McLaurin KA, Booze RM, Mactutus CF. Evolution of the HIV-1 transgenic rat: utility in assessing the progression of HIV-1-associated neurocognitive disorders. J Neurovirol. 2018;24:229-45.

97. Vigorito M, Connaghan KP, Chang SL. The HIV-1 transgenic rat model of neuroHIV. Brain Behav Immun. 2015;48:336-49.

98. Reid WC, Ibrahim WG, Kim SJ, Denaro F, Casas R, Lee DE, et al. Characterization of neuropathology in the HIV-1 transgenic rat at different ages. J Neuroimmunol. 2016;292:116-25.

99. Denaro F, Benedetti F, Worthington MD, Scapagnini G, Krauss CC, Williams S, et al. The HIV-1 transgenic rat: relevance for HIV noninfectious comorbidity research. Microorganisms. 2020;8:1643.

100. Gu CJ, Borjabad A, Hadas E, Kelschenbach J, Kim BH, Chao W, et al. EcoHIV infection of mice establishes latent viral reservoirs in $\mathrm{T}$ cells and active viral reservoirs in macrophages that are sufficient for induction of neurocognitive impairment. PLoS Pathog. 2018;14:e1007061. 
101. Potash MJ, Chao W, Bentsman G, Paris N, Saini M, Nitkiewicz J, et al. A mouse model for study of systemic HIV-1 infection, antiviral immune responses, and neuroinvasiveness. Proc Natl Acad Sci U S A. 2005;102:3760-5.

102. Kelschenbach J, He H, Kim BH, Borjabad A, Gu CJ, Chao W, et al. Efficient expression of HIV in immunocompetent mouse brain reveals a novel nonneurotoxic viral function in hippocampal synaptodendritic injury and memory impairment. mBio. 2019;10:e00591-19.

103. Honeycutt JB, Garcia JV. Humanized mice: models for evaluating NeuroHIV and cure strategies. J Neurovirol. 2018;24:185-91.

104. Fauci AS, Desrosiers RC. Pathogenesis of HIV and SIV. In: Coffin JM, Hughes SH, Varmus HE, editors. Retroviruses. New York: Cold Spring Harbor;1997.

105. Williams K, Lackner A, Mallard J. Non-human primate models of SIV infection and CNS neuropathology. Curr Opin Virol. 2016;19:92-8.

106. Clarke S, Berry N, Ham C, Alden J, Almond N, Ferguson D. Neuropathology of wild-type and nef-attenuated $\mathrm{T}$ cell tropic simian immunodeficiency virus (SIVmac32H) and macrophage tropic neurovirulent SIVmac17E-Fr in cynomolgus macaques. J Neurovirol. 2012;18:100-12.

107. Smith MO, Heyes MP, Lackner AA. Early intrathecal events in rhesus macaques (Macaca mulatta) infected with pathogenic or nonpathogenic molecular clones of simian immunodeficiency virus. Lab Invest. 1995; 72:547-58.

108. Matsuda K, Riddick NE, Lee CA, Puryear SB, Wu F, Lafont BAP, et al. A SIV molecular clone that targets the CNS and induces neuroAIDS in rhesus macaques. PLoS Pathog. 2017;13:e1006538.

109. Lee CA, Beasley E, Sundar K, Smelkinson M, Vinton C, Deleage C, et al. Simian immunodeficiency virusinfected memory $\mathrm{CD} 4^{+} \mathrm{T}$ cells infiltrate to the site of infected macrophages in the neuroparenchyma of a chronic macaque model of neurological complications of AIDS. mBio. 2020;11:e00602-20.

110. Sil S, Thangaraj A, Chivero ET, Niu F, Kannan M, Liao K, et al. HIV-1 and drug abuse comorbidity: lessons learned from the animal models of NeuroHIV. Neurosci Lett. 2021;754:135863.

111. Fitting S, McRae M, Hauser KF. Opioid and neuroHIV comorbidity-current and future perspectives. J Neuroimmune Pharmacol. 2020;15:584-627.

112. Yao H, Buch S. Rodent models of HAND and drug abuse: exogenous administration of viral protein(s) and cocaine. J Neuroimmune Pharmacol. 2012;7:341-51.

113. Yan X, Gong Z, Pan R, Wang H, Tang H, He H, et al. Synergistic effect and mechanism of apoptosis induction by morphine and the HIV-1gp120V3 loop in hippocampal neurons. J Neuroimmune Pharmacol. 2021; [Epub ahead of print].

114. Weed M, Adams RJ, Hienz RD, Meulendyke KA, Linde ME, Clements JE, et al. SIV/macaque model of HIV infection in cocaine users: minimal effects of cocaine on behavior, virus replication, and CNS inflammation. J Neuroimmune Pharmacol. 2012;7:401-11. 